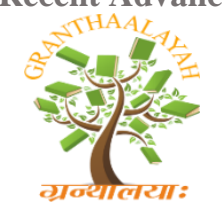

$$
\begin{gathered}
\text { INTERNATIONAL JOURNAL OF RESEARCH - } \\
\text { GRANTHAALAYAH } \\
\text { A knowledge Repository }
\end{gathered}
$$

RACEEE - 17

\title{
INTELLIGENT ENGINE SYSTEM FOR TRAIN BY USING ARDUINO UNO KIT WITH THE GENERATION OF ELECTRICITY USING SOLAR AND WIND ENERGY
}

\author{
G.B.Praveen ${ }^{1}$, Jayashri.P ${ }^{2}$, Manasa M Shetty ${ }^{3}$ \\ ${ }^{* 1}$ Assistant Professor, Department of E \& E, YIT, Mangalore, India
}

DOI: https://doi.org/10.29121/granthaalayah.v5.i4RACEEE.2017.3325

\begin{abstract}
The railway network of India is the biggest in South Asia and perhaps the most complicated in all over the world. There are so many different types of train local, fast, super-fast, passenger, goods etc. and there are so many multiple routes. Although the time table is perfect it is not at all possible to maintain it. And that's why the train accidents are becoming more and more usual. So a kind of intelligence of the train engines itself, so that it prevents accidents. In our project we aim at generating electricity using combined renewable energy resources of wind and solar from a running train and using a part of this energy to detect damages in the railway track system by passing a minute voltage over the track, thus avoiding the train accidents. Remaining energy can be saved using battery and used for train lighting system. We also aim at avoiding the other different possibilities of train accidents. Such as accidents due to signal miscommunication, accident due to moving or stationary objects across the track using MATLAB.
\end{abstract}

Keywords: Mat lab; Arduino Uno Kit; Solar Panel.

Cite This Article: G.B.Praveen, Jayashri.P, and Manasa M Shetty. (2017). "INTELLIGENT ENGINE SYSTEM FOR TRAIN BY USING ARDUINO UNO KIT WITH THE GENERATION OF ELECTRICITY USING SOLAR AND WIND ENERGY." International Journal of Research - Granthaalayah, 5(4) RACEEE, 68-78. https://doi.org/10.29121/granthaalayah.v5.14RACEEE.2017.3325.

\section{Introduction}

Train accidents occur normally due to safety violations resulting from ,human errors or limitations ${ }^{\text {ee }}$ and „equipment failures ${ }^{\text {ee }}$ loosing precious lives. The Ministry of Railways (Railway Board), Govt. of India has referred for developing an efficient Train Anti-Collision system. The goal of this work is to design and implement a cost effective and intelligent full-fledged microcontroller and wireless based Train Anti Collision System to successfully prevent the train collisions. It aims to efficiently integrate into the existing signalling system and avoid accidents 
Recent Advances in Communication, Electronics \& Electrical Engineering

in manned as well as unmanned level crosses, without changing any of the existing system implemented in Indian Railway. We also aim at avoiding the different possibilities of train accidents such as accidents due to stationary object across the track using MATLAB, accident due to damage of track and we provide wireless communication for the engine system to slow down at receiving station.

The second part of the project aim at generating electricity using combined renewable energy resources of wind and solar from a running train.

SOLAR: INDIA receives a solar energy equivalent of 5000 trillion $\mathrm{kWh}$ per year with daily average solar energy incidence of 4 to $7 \mathrm{kWh}$ per meter square. This is considerably more than the total energy consumption of the country. Solar energy with its virtually infinite potential and free availability represents a non-polluting and inexhaustible energy sources which can be developed to meet the energy needs of mankind in a major way. The high cost, fast depleting fossil fuels and public concern about the eco-friendly power generation of power have led to surge of interest in the utilization of solar energy.

WIND: The development of wind power in INDIA began in the 1990s, and has significantly increased in the last few years. Wind power is the use of airflow through wind turbines to mechanically power generators for electricity. Wind power, as an alternative to burning fossil fuels, is plentiful, renewable, widely distributed, clean, produces no greenhouse gas emissions during operation and uses little land. The net effects on the environment are far less problematic than those of non-renewable power sources.

In this project we aim at generating electricity using combined renewable energy resources of wind and solar from a running train and using a part of this energy to detect damages in the railway track system by passing a minute voltage over the tracks using wheels of the train, thus avoiding the train accidents. Remaining energy can be saved using battery and used for train lighting system.

ENERGY RESOURCES SOLAR AND WIND: Energy is playing an important role in human and economic development. One of the driving forces for social and economic development and basic demand of nation is energy. Most of the energy production methods are one-way, which requires change of form for the energy. In parallel to developing technology, demand for more energy makes us seek new energy sources. Researches for renewable energies have been initiated first for wind power and then for solar power. Efficiency of solar power conversion system is calculated to be $18 \%$ while that of wind power is calculated to be $55 \%$. INDIA is a large country and rate of electrification has not kept pace with the expanding population, urbanization and industrialization and has resulted in the increasing deficit between demand and supply of electricity.

\section{Methodology}

The block diagram is mainly divided into two parts, they are receiver part and transmitter part as shown below. 
Recent Advances in Communication, Electronics \& Electrical Engineering

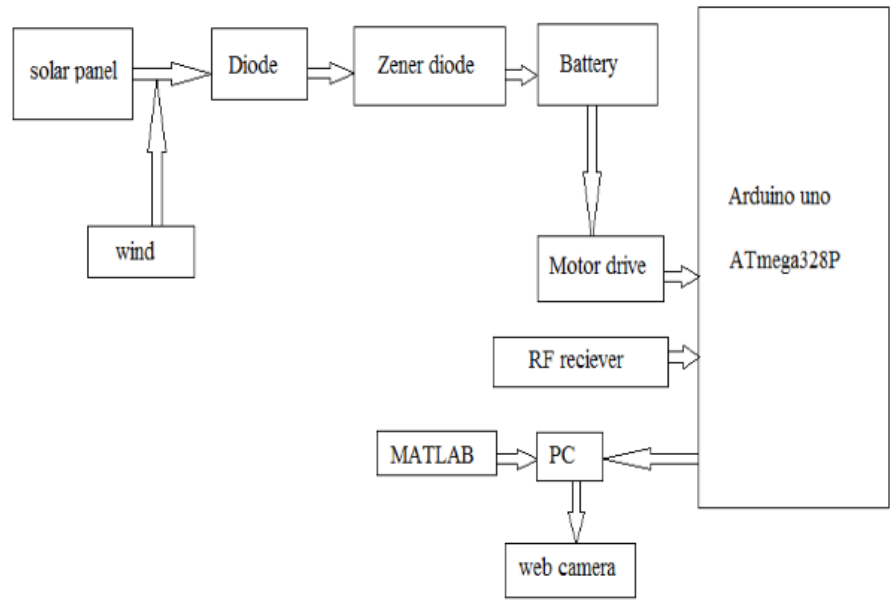

Figure 1: Block diagram of receiver part of train

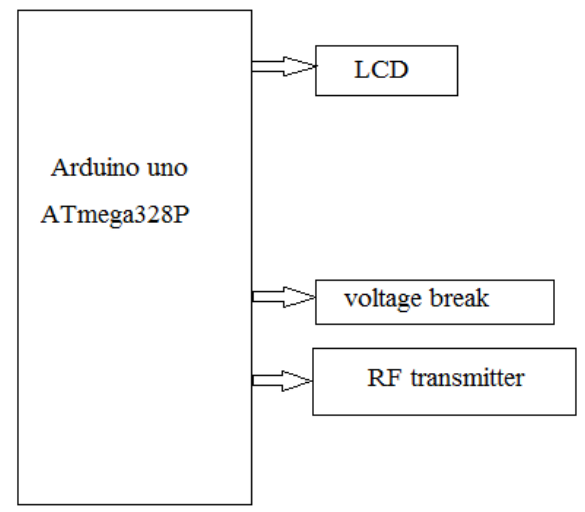

Figure 2: Block diagram of transmitter part of train

\section{Working}

In this project we are using arduino uno as a controller which controls the various input and output signals. Both the transmitter and receiver are of RF type with minimum range so that train can get enough time to decrease its speed and stop before the signal pole. When a moving object is detected the data is sent through serial interface using MATLAB. We can get the output with the images shown by the web camera, So that the driver gets alerted. A minute voltage of below $5 \mathrm{~V}$ is passed through the track to check the gap or any damage in the railway tracks. The signal is then received by the controller and it gives alarm with LCD display. Thus we can avoid the different possibility of train collision. We are generating the electricity in train using combined sources of wind and solar. When the train is running on the track the generated wind and solar panel provided on the top of train, combined and used to generate electrical energy. This energy can be stored in battery and used.

As per the objective we have designed the above functional diagram. Its working is as follows,

- CONTROLLER: We use ARDUINO UNO as a controller which receives signal from various input and output devices and control its operations based on the signal received.

- POWER SUPPLY (6 to 8V): It is used to give input supply to the kit. 
Recent Advances in Communication, Electronics \& Electrical Engineering

- MATLAB: This software is used to identify the object across railway track.

- WEBCAMERA: It is used to capture the images of detected object on track in various angles.

- RADIO FREQUENCY RECEIVER AND TRANDMITTER: The control signal from the

- train is transmitted to the station using RF transmitter and received by the receiver at the station.

- LIQUID CRYSTAL DISPLAY: To display the output detected.

- SOLAR PANEL with WIND (FAN) HYBRID ENERGY SYSTEM: To generate electricity

- from a running train. Here we are placing solar panel on the top of the train and fans are placed at sides of the train window panes. The combined energy of solar and wind is use to generate electricity through generating part.

- BATTERY: To store the energy that is generated from the solar panel and wind hybrid energy system.

\section{Functional Description}

\section{ARDUINO UNO KIT:}

The Arduino Uno is a microcontroller board based on the ATmega328. It has 14 digital input/output pins (of which 6 can be used as PWM outputs), 6 analog inputs, a $16 \mathrm{MHz}$ crystal oscillator, a USB connection, a power jack, an ICSP header, and a reset button. It contains everything needed to support the microcontroller; simply connect it to a computer with a USB cable or power it with a AC-to-DC adapter or battery to get started. The Uno differs from all preceding boards in that it does not use the FTDI USB-to-serial driver chip. Instead, it features the Atmega8U2 programmed as a USB-to-serial converter. "Uno" means one in Italian and is named to mark the upcoming release of Arduino 1.0. The Uno and version 1.0 will be the reference versions of Arduino, moving forward.

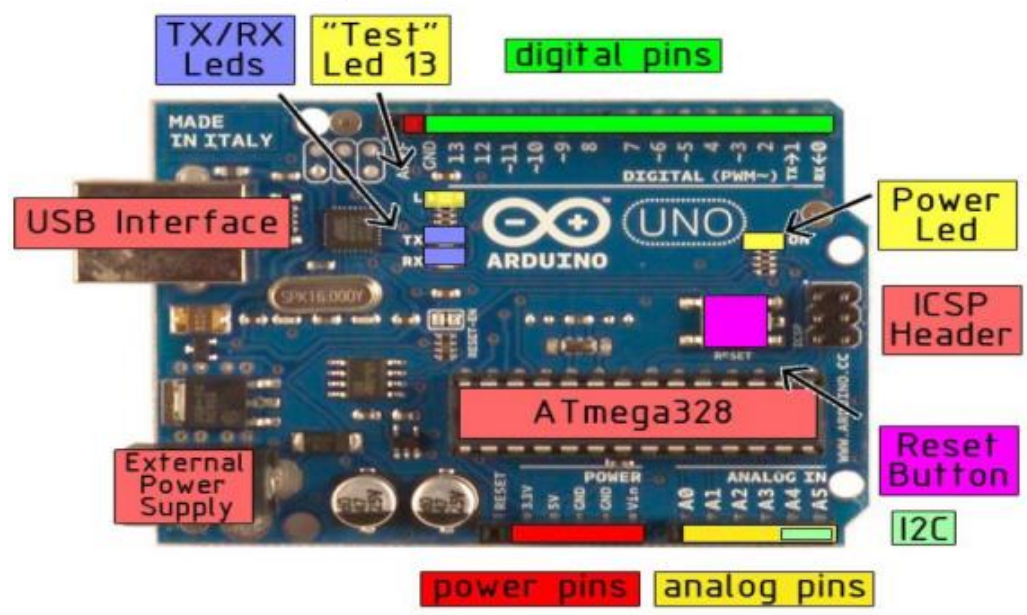

Figure 3: Arduino Uno kit

\section{POWER IN ARDUINO:}

The Arduino Uno can be powered via the USB connection or with an external power supply. The power source is selected automatically. External (non-USB) power can come either from an AC- 
Recent Advances in Communication, Electronics \& Electrical Engineering to-DC adapter (wall-wart) or battery. The adapter can be connected by plugging a $2.1 \mathrm{~mm}$ centerpositive plug into the board's power jack. Leads from a battery can be inserted in the ground and Vin pin headers of the power connector. The board can operate on an external supply of 6 to 20 volts. If supplied with less than $7 \mathrm{~V}$, however, the $5 \mathrm{~V}$ pin may supply less than five volts and the board may be unstable. If using more than $12 \mathrm{~V}$, the voltage regulator may overheat and damage the board. The recommended range is 7 to 12 volts.

\section{USB OVERCURRENT PROTECTION:}

The Arduino Uno has a resettable poly fuse that protects your computer's USB ports from shorts and overcurrent. Although most computers provide their own internal protection, the fuse provides an extra layer of protection. If more than $500 \mathrm{~mA}$ is applied to the USB port, the fuse will automatically break the connection until the short or overload is removed.

\section{RF TRANSMITTER AND RECEIVER:}

$\mathrm{RF}$ module, as the name suggest operates at radio frequency. The corresponding frequency range varies between $30 \mathrm{kHz}$ and $300 \mathrm{GHz}$. In this $\mathrm{RF}$ system, the digital data is represented as variation in amplitude of carrier wave. This kind of modulation is known as Amplitude Shift Keying (ASK). Transmission through RF is better than IR because of many reasons. Firstly, signal through the RF can travel through larger distance making it suitable for long range application. Also, while IR mostly operates in line of sight modes, RF signals can travel even when there is an abstraction between transmitter and receiver. Next RF transmission is most strong and reliable than IR transmission. RF communication uses a specific frequency unlike IR signals which are affected by other IR emitting sources. This RF module comprises of an RF transmitter and receiver. The TX/RX pair operated at a frequency of $434 \mathrm{MHz}$.An RF transmitter receives serial data and transmit it wirelessly through RF through its antenna pin. The transmission occurs at the rate of $1 \mathrm{kbps}-10 \mathrm{kbps}$. The transmitted data is received by an RF receiver operating at a same frequency as that of the transmitter.

\section{Pin diagram:}

Pin description:

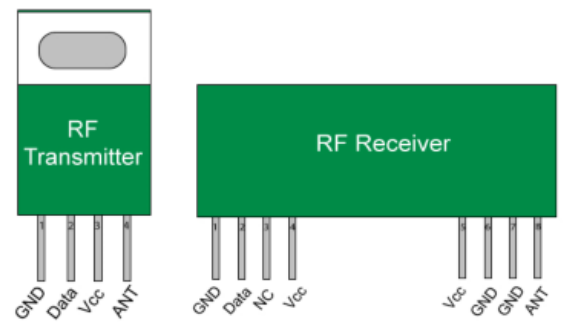

Figure 4: RF receiver and transmitter

\section{RF Transmitter:}

Table 1: RF transmitter pin description

\begin{tabular}{|c|l|c|}
\hline Pin No & \multicolumn{1}{|c|}{ Function } & Name \\
\hline 1 & Ground (0 volt) & GND \\
\hline 2 & Serial Data Input pin & Data \\
\hline 3 & Supply Voltage (5 Volt) & VCC \\
\hline 4 & Antenna Input pin & ANT \\
\hline
\end{tabular}


Recent Advances in Communication, Electronics \& Electrical Engineering

Table 2: RF receiver pin description

\begin{tabular}{|c|l|c|}
\hline Pin No & \multicolumn{1}{|c|}{ Function } & Name \\
\hline 1 & Ground (0 Volt) & GND \\
\hline 2 & Serial Data Output pin & Data \\
\hline 3 & Linear Output Pin; not connected & NC \\
\hline 4 & Supply Voltage (5 Volt) & VCC \\
\hline 5 & Supply Voltage (5 Volt) & GND \\
\hline 6 & Ground (0 Volt) & GND \\
\hline 7 & Ground (0 Volt) & ANT \\
\hline 8 & Antenna Input pin & \\
\hline
\end{tabular}

\section{LCD (LIQUID CRYSTAL DISPLAY):}

A $16^{*} 2$ LCD pin display 16 characters per line and there are two such lines. In this LCD each character is display in 5*7 pixel matrix. This LCD as two resistors, namely, command and data.The command resistor stores the command instructions given to the LCD. A command is an instruction given to LCD to do a predefined task like initializing it, clearing its screen, setting the cursor position, controlling display etc. the data resistor stores the data to be display on the LCD. The data is the ASCII value of the character to displayed on the LCD.

\section{Pin Description:}

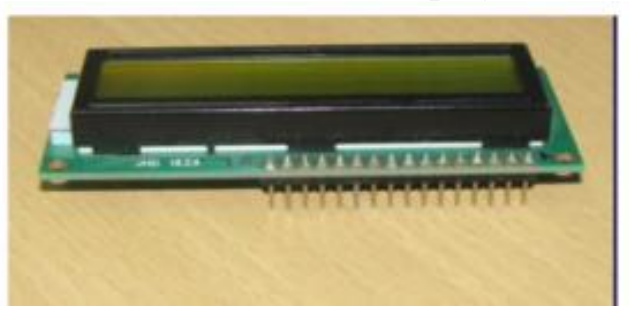

Figure 5: Liquid crystal display

Table 3: Pin description of liquid crystal display

\begin{tabular}{|c|c|c|}
\hline Pin No & Function & Name \\
\hline 1 & Ground & GND \\
\hline 2 & Supply Voltage (5 volt) & $\mathrm{VCC}$ \\
\hline 3 & Contrast Adjustment ; through a variable resistor & VEE \\
\hline 4 & $\begin{array}{l}\text { Selects command resistor when low; and data } \\
\text { resistor when high }\end{array}$ & Resistor select \\
\hline 5 & $\begin{array}{l}\text { Low to write to the resistor ;high to read from the } \\
\text { resistor }\end{array}$ & Read/Write \\
\hline 6 & $\begin{array}{l}\text { Sends data to data pins then high to low pulse is } \\
\text { given }\end{array}$ & Enable \\
\hline 7 & \multirow{8}{*}{ 8-bits data pin } & DB0 \\
\hline 8 & & DBI \\
\hline 9 & & DB2 \\
\hline 10 & & DB3 \\
\hline 11 & & DB4 \\
\hline 12 & & DB5 \\
\hline 13 & & DB6 \\
\hline 14 & & DB7 \\
\hline 15 & \begin{tabular}{|l|} 
Backlight VCC (5 volt) \\
\end{tabular} & LED+ \\
\hline 16 & Backlight ground ( 0 volt) & LED- \\
\hline
\end{tabular}


Recent Advances in Communication, Electronics \& Electrical Engineering

SOLAR PANEL:

Solar panel refers to a panel designed to absorb the sun ${ }^{\text {ee }}$ s rays as a source of energy for generating electricity or heat. A photovoltaic (PV) module is a package, connected assembly of solar cells. Solar photovoltaic panels constitute the solar array of a photovoltaic system that generates and supplies solar electricity in commercial and residential applications. A photovoltaic system includes a panel or an array of solar modules, solar inverter and sometimes a battery or solar tracker in inters connection wiring.

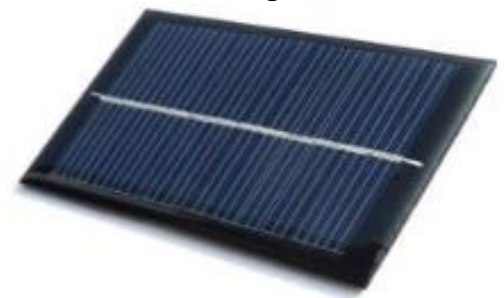

Figure 6: Solar panel

FAN:

To represent the generation of electricity from the wind.

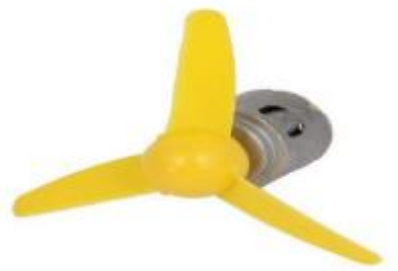

Figure 7: Fan

\section{ZENER DIODE:}

The zener diode is the simplest types of voltage regulator and the point at which the zener diode breakdown or conducts is called "Zener voltage" (Vz). The zener diode is like a general purpose signal diode consisting of a silicon PN junction. When biased in the forward direction it behaves just like a normal signal diode causing the rated current, but as soon as reversed voltage applied across the zener diode exceeds the rated voltage of the device, the diode breakdown voltage is reached at which point a process called "Avalanche Breakdown" across in the semi-conductor depletion layer and a current starts to flow through the diode to limit this increase in voltage.

\section{DIODE:}

1N4001 is a member of 1N400x diodes. Diode is a rectifying device which conducts only from anode to cathode. Diode behaves open circuited for the current flow from cathode to anode. 1N4001 is a 1A diode with low forward voltage drop and high surge current capability. It comprises of diffused PN junction and has low reserve leakage current of $5 \mu \mathrm{A}$. its DC blocking voltage is $50 \mathrm{~V}$.

\section{MOTOR IC DRIVE:}

L293D is a dual H-BRIDGE motor drive integrated circuit. Motor drives act as current amplifiers since they take a low-current control signal and provide a higher-current signal. This higher current signal is used to drive the motors. 
Recent Advances in Communication, Electronics \& Electrical Engineering

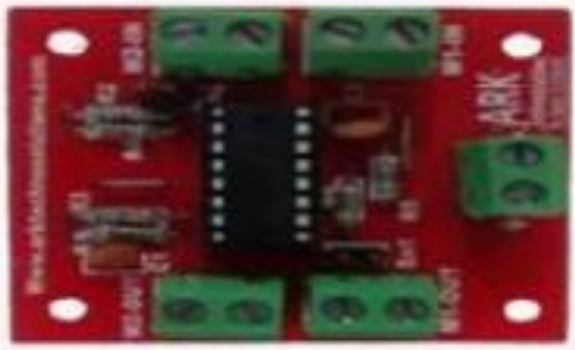

\section{Pin description:}

Figure 6: DC motor IC drive

Table 4: Pin description of DC motor IC drive

\begin{tabular}{|c|l|c|}
\hline $\begin{array}{c}\text { Pin } \\
\text { number }\end{array}$ & \multicolumn{1}{|c|}{ Function } & Name \\
\hline 1 & Enable pin for Motor 1; active high & Enable 1,2 \\
\hline 2 & Input I for Motor I & Input 1 \\
\hline 3 & Output I for Motor I & Output I \\
\hline 4 & Ground (0V) & Ground \\
\hline 5 & Ground (0V) & Output 2 \\
\hline 6 & Output 2 for Motor I & Input 2 \\
\hline 7 & Input 2 for Motor I & VCC2 \\
\hline 8 & Supply Voltage for Motors,9-12V(up to 36V) & Enable 3,4 \\
\hline 9 & Enable pin for Motor 2;active high & Input 3 \\
\hline 10 & Input I for Motor I & Output 3 \\
\hline 11 & Output I for Motor I & Ground \\
\hline 12 & Ground (0V) & Output 4 \\
\hline 13 & Ground (0V) & Input 4 \\
\hline 14 & Output 2 for Motor I & VCC1 \\
\hline 15 & Input 2 for Motor I & \\
\hline 16 & Supply voltage; 5V ( up to 36V) & \\
\hline
\end{tabular}

\section{WEB CAMERA:}

A web camera is a video camera that feeds or streams its image in real time to or through a computer to computer network. When captured by a computer, the video stream may be saved, viewed or sent onto other networks via systems such as internet an email as an attachment. When sent to remote location, the video stream may be saved, viewed or on sent there. A web camera is generally connected by a USB cable, or similar cable, or built into computer hardware, such as laptops. They have also become a source of security and privacy issues, as some built in webcams can be remotely activated via spyware.

\section{BATTERY:}

A primary cell is a battery that is designed to be used once and discarded, and not recharged with electricity and reused like a secondary cell. In general, the electrochemical reaction occurring in the cell is not reversible, rendering the cell rechargeable. As a primary cell is used, chemical reaction in the battery use up the chemicals that generate the power; when they are gone, the battery stops producing electricity and is useless. In contract, in a secondary cell, the reaction can be reserved by running a current into cell with a battery charger to recharge it, regenerating the chemical reactants. Primary cells are made in a range of standard sizes to power small household appliances. 
Recent Advances in Communication, Electronics \& Electrical Engineering

\section{RECHARGEABLE BATTERY:}

A rechargeable battery, storage battery, secondary cell, or accumulator is a type of electrical battery which can be charged, discharged into a load, and recharged many times, while a nonrechargeable or primary battery is supplied fully charged, and discarded once discharged. It is composed of one or more electrochemical cells. The term "accumulator" is used as it accumulates and stores energy through a reversible electrochemical reaction.

Rechargeable batteries are produced in many different shapes and sizes, ranging from button cells to megawatt systems connected to stabilize an electrical distribution network. Several different combinations of electrode materials and electrolytes are used, including leadacid, nickel-cadmium, nickel metal hybrid, Lithium ion, and lithium ion polymer.

\section{Circuit Diagram}

\section{CIRCUIT DIAGRAM OF TRANSMITTER:}

In the station, we used Arduino Uno kit to give signal to the transmitter. Transmitter has 4 pins GND, DATA, VCC and ANT.LCD is connected to the Arduino it is used to display messages which is installed in the receiving station. Circuit diagram for the above process is shown below

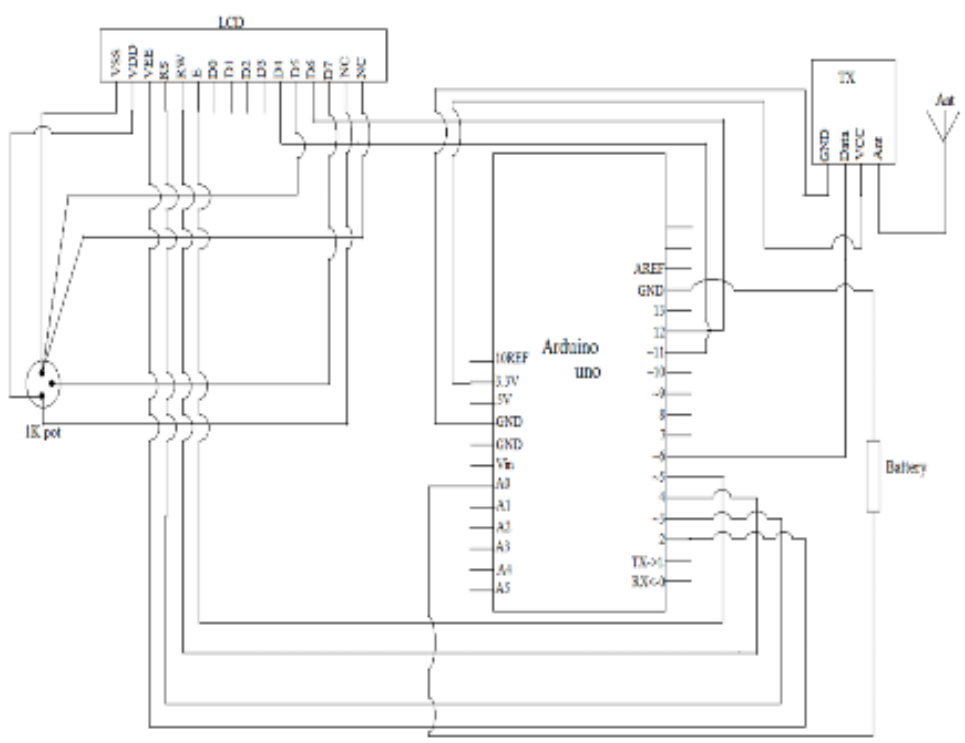

Figure 7: Transmitter diagram of the station

\section{CIRCUIT DIAGRAM OF RECEIVER:}

The main component in this project is Arduino Uno kit series ATmega328P. here we used DC motor drive to run the train motor. The supply is given from the Arduino Uno of 3.3V. Receiver is also connected to the Arduino. It is used to receive the signal. Using program we send receiver the data to stop the train after getting the signal and due to this automatic operation it reduces the speed. Circuit diagram for the above process is shown below 
Recent Advances in Communication, Electronics \& Electrical Engineering

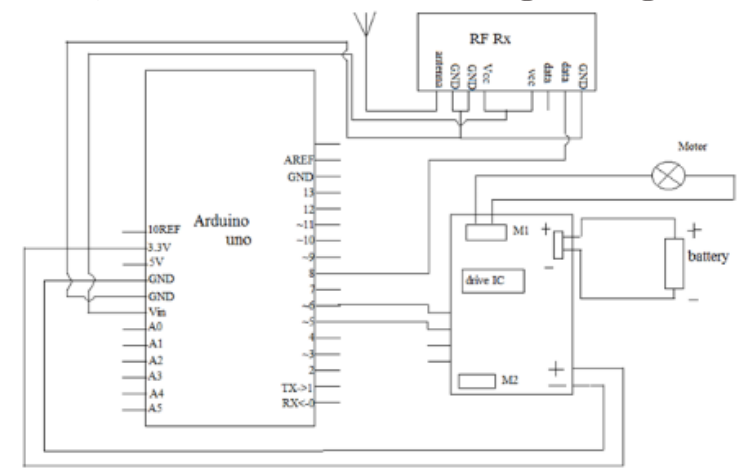

Figure 8: Receiver diagram of the train engine system

\section{CIRCUIT DIAGRAM OF POWER GENERATION:}

In this project we are installing solar panel on the top of the train and fans on the side of the train. By collecting the radiations of sun by the solar panel and wind that is generated when the train is running. There by we can generate electricity and stores that energy in the battery. The generation level of both the source is in different level. so, to make it constant we used diode and zener diode. Circuit diagram for the above process is shown below

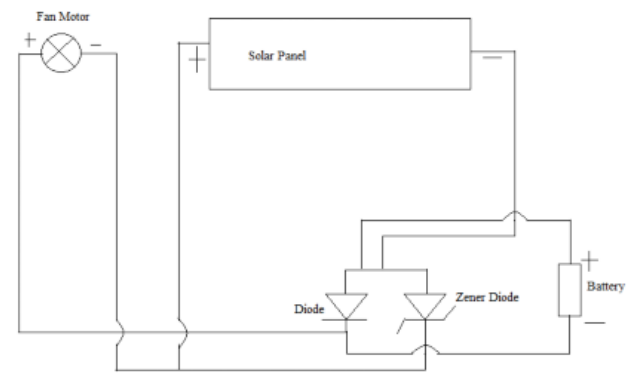

\section{Result}

Figure 9: Diagram of generating part of electricity

Generation of electricity using solar and wind energy. The speed of the train reduces automatically when it reaches to the respective (receiving) station. It can easily detect the breakage of the track by passing the minute voltage through track. Detection of image across the track using web camera can alert the driver to prevent the accidents.

\section{Advantages \& Applications}

\section{ADVANTAGES:}

- Automatic operation

- Prevent accidents

- Safety to the peoples

- Fault analyze is easy

- Running cost effective

- Low power consumption

- Easy installation

- No wastage of man-power 
Recent Advances in Communication, Electronics \& Electrical Engineering

\section{APPLICATION:}

This design can be implemented together in the train engine as well as at level crossing. To avoid the accidents up to the maximum extent. We can generate electricity in the running train using renewable resources such as solar and wind energy. The Global Positioning System module will help the travellers to know their exact location.

\section{Conclusion \& Future Scope}

\section{CONCLUSION}

The features implemented in this project such as generating electricity using solar and wind energy can be used for lighting system of train. The design and implementation cost is effective and intelligent full-fledged Arduino controller and wireless based Train Anti Collision System to successfully prevent the train collisions has been done.

\section{FUTURE SCOPE}

We can improve the performance of train engine such that when object is detected the engine itself gets slowdown. Voltage breakdown for automatic control of engine system. We can also include GSM module system.

\section{References}

[1] Collision detection and avoidance of railway traffic. Arun.P, Saritha.S, engineer-E, NIELIT Kerala-[2012].

[2] Implementation of ZigBee Based Train Anti -Collision and Level Crossing Protection System for Indian Railways. Careena P, Arun P, Sabarinath G, Madhukumar S [IJLTET][2013].

[3] Intelligent train engine for the fastest new age technology. Anil Kumar Varma, Dharmendra kumar, Gopal Krishna Gole, Jitendra Kumar-[2013].

[4] Intelligent system for train engine with automatic gate controlling using wireless technology, KAWSHIK SHIKDER, Department of EEE ,American international university in Bangladesh[IJSR]-[2014].

\section{Authors}

G.B.Praveen is an Assistant Professor from the Dept. of Electrical and Electronics, YIT, Mangalore. (E-mail: gbpraveen.995@gmail.com). And received his M.Tech degree with specialization in Computer Applications in Industrial Drives from NIE, Mysore. He is having 5years of industrial experience in electrical field.

Jayashri P. is an Assistant Professor from the Dept. of Electrical and Electronics, YIT, Mangalore. (E-mail: jsp_05@yahoo.co.in). And received her M.Tech degree with specialization in Power Electronics from St. Joseph Engineering College, Mangalore.

Manasa M Shetty is an Assistant Professor from the Dept. of Electrical and Electronics, YIT, Mangalore. (E-mail: sheetty.manasa10@gmail.com). And received her M.Tech degree with specialization in Power Electronics from St. Joseph Engineering College, Mangalore.

*Corresponding author.

E-mail address: gbpraveen.995@gmail.com 